\title{
Synthesis of metal nanoparticles using Heliconia rostrata leaf extract and their antiproliferative and apoptotic property
}

\author{
Lingappa Mallesha ${ }^{a^{*}}$, Guruswamy Vinay a and Nanjappagowda Dharmappa Rekhab
}

${ }^{a} P G$ Department of Chemistry, JSS College of Arts, Commerce and Science, B. N. Road, Mysuru-25, India ${ }^{b} P G$ Department of Biotechnology, JSS College of Arts, Commerce and Science, B. N. Road, Mysuru-25, India

\begin{tabular}{l}
\hline C H R O N I C L E \\
\hline Article history: \\
Received December 22, 2017 \\
Received in revised form \\
April 12, 2018 \\
Accepted April 12, 2018 \\
Available online \\
April 12, 2018 \\
\hline Keywords: \\
Heliconia rostrate \\
Nanoparticles \\
Anti-proliferative activity
\end{tabular}
\begin{abstract}
A B S T R A C T
The silver and gold nanoparticles were biosynthesized using leaves of a pharmacologically important plant Heliconia rostrata. A rapid, eco-friendly, cost-effective and one-step process of synthesis has been achieved, thus produced nanoparticles were characterized by UV-visible, FT-IR, XRD and TEM spectral studies. Further, newly synthesized nanoparticles were used to study the induction of apoptotic activity on EAT cells. These two type of nanoparticles showed antiproliferative and apoptotic property in mice model. The outcome of this study could be useful for the development of value added products from indigenous medicinal plants, which has biomedical applications.
\end{abstract}

\section{Introduction}

The growth of green biosynthesis for the production of nanoparticles is evolving into an important branch of nanotechnology. ${ }^{1}$ Numerous methodologies are developed to synthesize noble metal nanoparticles of particular shape and size depending on specific requirements. Biosynthesis of nanoparticles has an emerging highlight of the intersection of nanotechnology and biotechnology which has received increased attention to a growing need to develop environmentally benign technologies in material syntheses. Biomolecules as reductants are found to have significant advantage over chemical reductants due to their biocompatible nature. ${ }^{2}$ The scientific and technological significance of metal nanoparticles has made them the subject of intensive research, given their special chemical and physical properties. Presently, biological nanoscience has increasing attention due to its advanced nature and the efficacy of produced nanoparticles, which are used as catalyst in industry. ${ }^{3}$ Silver nanoparticles have drawn the attention of scientists because of their extensive application in the development of new technologies in the areas of material sciences, electronics and medicine at the nanoscale. ${ }^{4}$ In particular, gold nanoparticles are employed in many fields, biosensing, ${ }^{5}$ electronics, ${ }^{6}$ enzyme electrodes, ${ }^{7}$ super conductors ${ }^{8}$ and cancer therapy. ${ }^{9}$ 
Tropical flowers never fail to amaze with their forms and colours. Heliconia rostrata (Lobster claw plant) is no exception, with large, brightly hued bracts that cluster up a stem. Heliconia rostrata is one of the most recognized and widely grown species. Heliconia lobster claw is also called parrot flower and has inconsequential tiny flowers covered by the showy bracts. ${ }^{10}$ Heliconia rostrata has a pendent inflorescence and the bracts are red with greenish yellow edges. It is a very popular species and one of the more common in cultivation. Heliconia rostrata flower extract has been used as an inhibitor for mild steel acid corrosion studies. ${ }^{11}$ In the present cram, a simple biosynthetic method using leaves extract of Heliconia rostrata is addressed herein for synthesizing silver and gold nanoparticles. The newly synthesized metal nanoparticles were characterized by employing standard spectral studies. Additionally, in vivo anti-proliferative and apoptotic assay has been evaluated.

\section{Results and Discussion}

\subsection{Characterization}

Formation of silver nanoparticles is apparent from the gradual change in colour of the incubated solution from colourless to dark brown and gold nanoparticles from colourless to dark purple. In contrast, colour of the control remained practically unchanged during the entire incubation period.
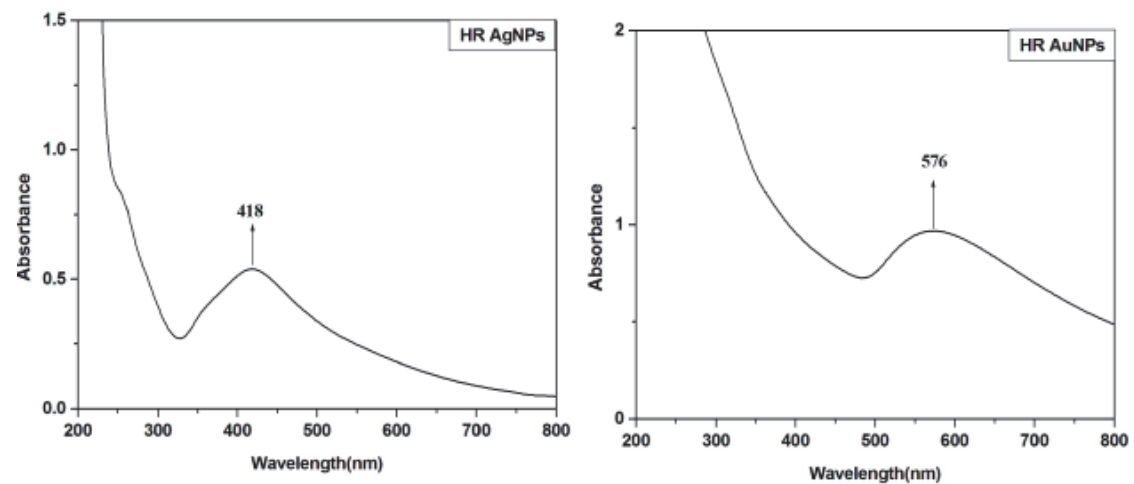

Fig. 1. UV-visible spectra of AgNPs and AuNPs

Fig. 1 shows a series of UV-Vis spectra of the solutions recorded at room temperature at intervals of $24 \mathrm{~h}$. All the spectra exhibit an intense peak at $576 \mathrm{~nm}$ (AuNPs) and $418 \mathrm{~nm}$ (AgNPs) corresponding to the metal nanoparticles. The reduction rate of $\mathrm{HAuCl}_{4}$ also varied and color intensity was changed due to the formation of gold nanoparticles.
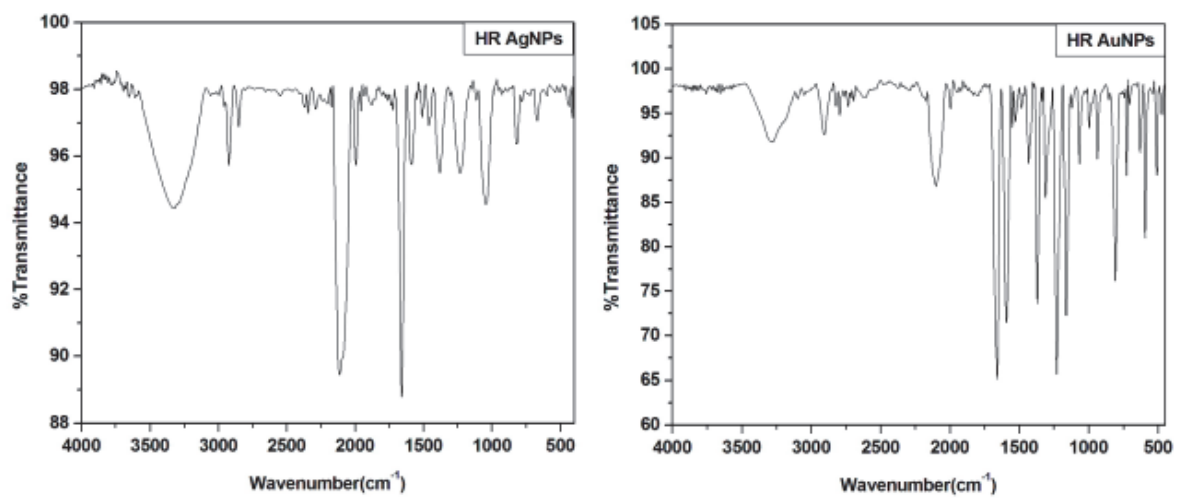

Fig. 2. FT-IR Spectra of AgNPs and AuNPs

Fourier transform infrared (FT-IR) was made in order to identify the possible biomolecules responsible for the reduction of metal ions and capping of the bioreduced metal nanoparticles (Fig. 2). 
The FT-IR spectrum of the silver and gold nanoparticles showed peaks at 3,318 and 3,277 (O-H stretch), 2,923 and 2,905 (C-H stretch), 2,113 and 2,100 (-C (triple bond) $\mathrm{C}-$ stretch of alkynes), 1,658 $\left(\mathrm{C}=\mathrm{O}\right.$ stretch of carboxylic acids), 1,046 and $1,064 \mathrm{~cm}^{-1}(\mathrm{C}-\mathrm{N}$ stretching vibration of aliphatic amines).

A structural analysis of metal nanoparticles prepared from the sample was performed by XRD. Taking into account the angular positions of the Bragg peaks (Fig. 3) were assigned to the silver and gold nanoparticles. The XRD pattern thus clearly illustrates that the metal nanoparticles synthesized by Heliconia rostrata are crystalline in nature. X-ray diffraction pattern AuNPs showed different peaks corresponding to the 38.04 (111), 43.98 (200), 64.30 (220) and 77.22 (311) planes. However, AgNPs have shown clear peaks of cubic phases at 38.06 (111), 44.27 (200), 64.56 (220) and 77.64 (311).
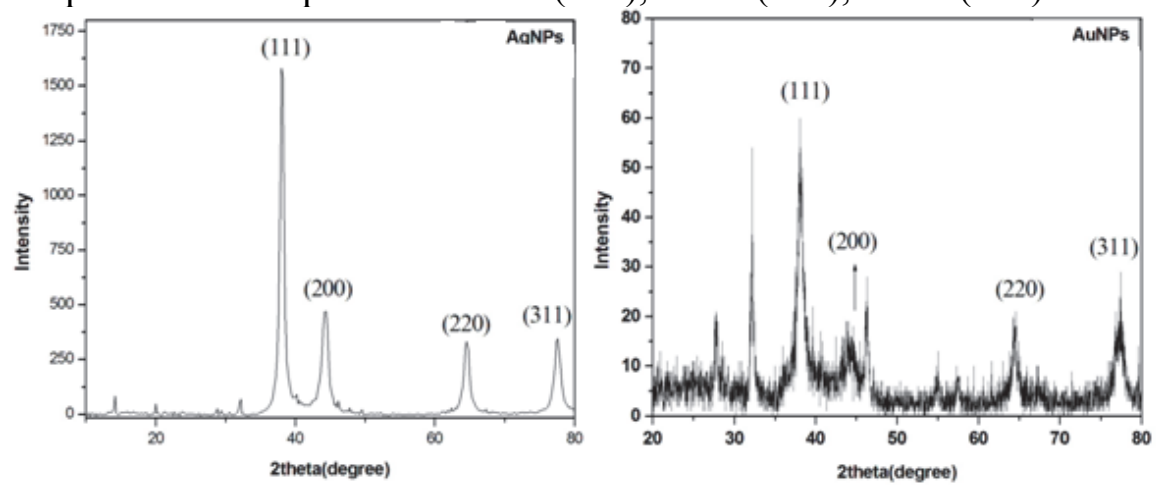

Fig. 3. XRD Spectra of AgNPs and AuNPs

TEM images of the metal nanoparticles produced by Heliconia rostrata leaf are shown in Fig. 4. The rate of silver nanoparticle formation is relatively slow when compared with that of gold nanoparticles.
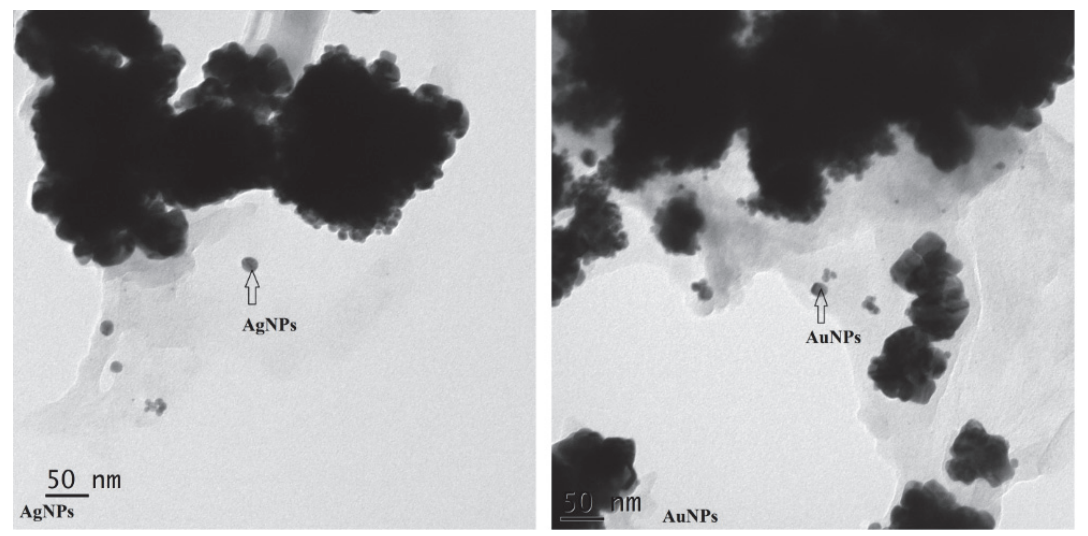

Fig. 4. TEM images of AgNPs and AuNPs

\subsection{Antiproliferative effect of silver and gold NPs in vivo}

\subsubsection{Culture of EAT cells in vivo and its effect on body weight}

EAT cells were grown in the peritoneal cavity of 6 to 8 -week-old Swiss albino mice by peritoneal transplantation of $0.5 \mathrm{ml}$ of cell suspension $\left(5 \times 10^{6}\right.$ cells $)$ in sterile saline. These cells grow in the mice peritoneum, forming an ascites tumor with massive abdominal swelling. The animals show a dramatic increase in body weight over the growth period and the animals succumb to the tumor burden by $12-$ 14 days after implantation. The number of cells increases gradually with the growth of tumor, along with accumulation of excess of ascites fluid in the peritoneum. To study the effect of the synthesized nanoparticles on the inhibition of proliferation of EAT cells in vivo, 2 groups of animals (control and treated) were selected and transplanted with EAT cells. A minimum of six mice in each group were 
used for the experiment and the results obtained are an average of three individual such experiments. From the day $6^{\text {th }}, 2 \mathrm{mg} / \mathrm{kg}$ body weight of the synthetic nanoparticles was injected intraperitoneally to the test animals, while the controls were injected with only PBS. The body weight of all the animals was monitored once in two days. After noting the body weight of the animals, on day $8^{\text {th }}, 10^{\text {th }}$ and $12^{\text {th }}$ batches of test and control animals were sacrificed by cervical dislocation and the abdominal cavity was dissected, exposing the peritoneum. The ascites fluid volume and the EAT cell count and morphology were noted.

\subsubsection{Measurement of ascites volume}

Since EAT cells grow as an ascites tumor, we measured the volume of ascites secreted from the control group treated with only PBS and the group that received the metal nanoparticles along with PBS. Ascites fluid along with the EAT cells was collected from both groups after opening up the peritoneal cavity with a median incision on the abdominal wall. The volume of ascites obtained from both the control and treated animals was noted.

Apoptoptotic activity: EAT cells were treated with gold and silver nanoparticles (Fig. 5) when stained with Giemsa stain and observed under microscope confirmed the activity of the nanoparticles. Blebbing of the nuclear and cytoplasmic membranes and few apoptotic bodies were seen. This activity of the nanoparticles on the EAT cells was further confirmed by acridine orange-ethedium bromide staining which demonstrated characteristic fluorescence under fluorescent microscope Fig. 6 . The weights of the treated animals showed a significant reduction as compared to the control animals as shown in the Table 1.

Table 1. Anti-proliferative effect of silver and gold NPs on body weight, ascites volume on EAT bearing mice

\begin{tabular}{lllll}
\hline & \multicolumn{5}{c}{ Day 12 after implantation } \\
\hline Treatment groups & $\begin{array}{l}\text { Control } \\
\text { (PBS) }\end{array}$ & $\begin{array}{l}\text { Treated (AgNPs) } \\
(\mathbf{2} \text { mg/Kg) }\end{array}$ & $\begin{array}{l}\text { Control } \\
\text { (PBS) }\end{array}$ & $\begin{array}{l}\text { Treated (AuNPs) } \\
(\mathbf{2} \text { mg/Kg) }\end{array}$ \\
\hline Weight of animals (gm) & $50.3 \pm 1.0$ & $39.5 \pm 0.8$ & $51.5 \pm 1.2$ & $39.3 \pm 1.3$ \\
Ascites volume (ml) & $2.7 \pm 0.9$ & $1.3 \pm 1.2$ & $5.6 \pm 0.3$ & $2.0 \pm 0.9$ \\
\hline
\end{tabular}
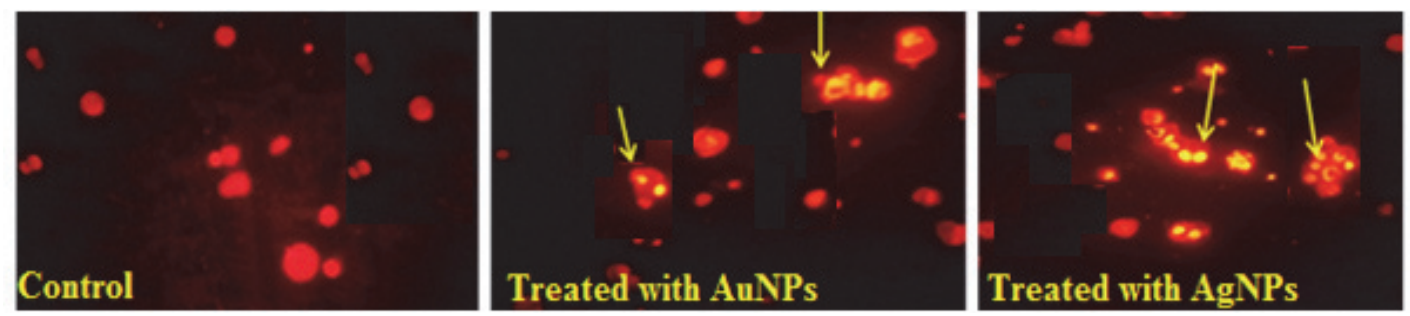

Fig. 5. Acridine orange and ethedium bromide staining of EAT cells after treatment with gold and silver NPs
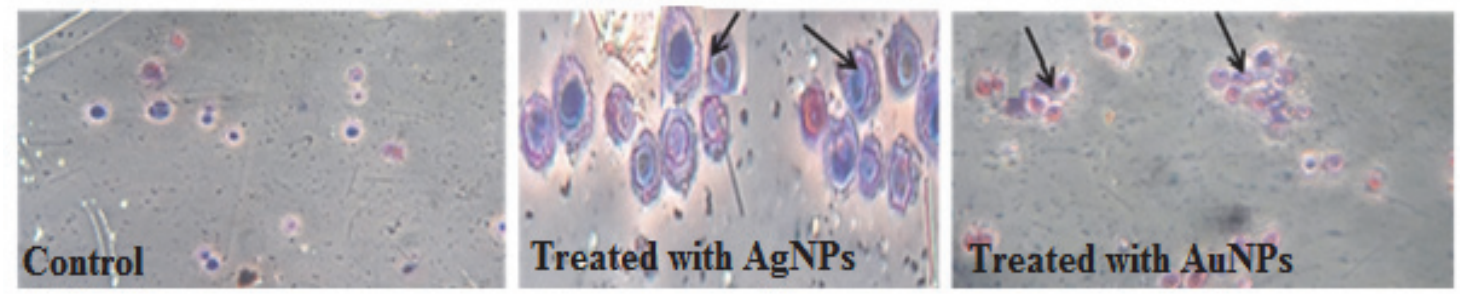

Fig. 6. Giemsa staining of EAT cells after treatment with gold and silver NPs 
The reaction of the ingredients present in the plant leaf extract analyzed by UV-visible spectroscopy revealed that silver nanoparticles in the solution may be correlated with the UV-vis spectra. This change of color indicates the formation of silver nanoparticles. Comparing both FT-IR spectra it can be identified that the changes in the $-\mathrm{COOH}$ group for $-\mathrm{OH}$, i.e., hydroxyl group the peak appeared at $3,214 \mathrm{~cm}^{-1}$ in raw material, but after encapsulation of nanoparticles, the peak is narrower and shifted to 3,318 and $3,277 \mathrm{~cm}^{-1}$ also for $-\mathrm{C}-$ of carboxylic group the peak intensity reduced after encapsulation of nanoparticles. Few peaks are reduced and the new peak appeared and it reduces $\mathrm{Ag}^{+}$to $\mathrm{Ag}^{0}$ and $\mathrm{Au}^{3+}$ to $\mathrm{Au}^{0}$, respectively. ${ }^{12}$ The sharpening of the peaks in XRD clearly indicates that the particles were in the nanoregime. ${ }^{13}$ A low magnification of TEM image recorded from the biologically synthesized nanoparticles at the end of the reaction with Heliconia rostrata leaf extract showed that the metal nanoparticles were predominantly circular in morphology. A large quantity of circular metal nanoparticles with thin, smooth ends on the exterior of the nanoparticles was seen in the TEM micrographs. ${ }^{14}$

The animals treated with nanoparticles showed a decrease in the body weight. The reduction in the body weights of the treated animals was due to decrease in tumour burden. The control animals treated with only the vehicle PBS, showed a much greater increase in the body weight, and this was significantly greater than the treated group of animals. There was a significant reduction of ascites volume noted in the treated group of animals as compared to the control animals. The animals treated with metal NPs showed a decrease in the amount of ascites fluid volume when compared to the control animals. The reduction in the amount of ascites fluid volume in the treated animals can also be explained by the decrease in tumour burden noted in the treated animals. Rosarin et al studied the anti-proliferative effect of amla extract mediated silver nanoparticles against cell lining. ${ }^{15}$ This study indicates that, Ag-NPs are capped with biomoecules of amla with enhanced cytotoxicity laryngeal cancer cells through oxidative stress and apoptotic function on Hep2 cancer cells.

\section{Conclusions}

The Heliconia rostrata aqueous leaf extract appears to be environmentally friendly and therefore this protocol could be used for the rapid production of metal nanoparticles. The Heliconia rostrata could be an excellent bioreductant and easily available plant source for green synthesis of silver and gold nanoparticles. The successful synthesis of metal nanoparticles by reducing silver and gold ions using an aqueous extract of Heliconia rostrata leaves showed that the reduction rate of silver ions is much faster than for gold. Nanoparticles were confirmed by UV-visible, TEM, XRD and FT-IR spectral technique. The anti-proliferative and induction of apoptotic activity of gold and silver nanoparticles on EAT cells was significantly reduced the tumor burden in EAT bearing mice. As the extract stabilized the nanoparticles and they can be a potential candidate for various biomedical applications.

\section{Acknowledgment}

One of the authors (L. Mallesha) is grateful to the DST-SERB, New Delhi, for financial support under Start up Research Grant (Young Scientist-Life Sciences), File No: YSS/2014/000888. The UVVisible data obtained from the instrument granted under DST-SERB project are greatly acknowledged. The Authors sincerely thank JSS Mahavidyapeeta \& JSS College of Arts, Commerce and Science, for providing research facilities to carry out this work.

\section{Experimental}

\subsection{Collection of materials for the study}

The leaves of Heliconia rostrata abundantly available in nature were collected without causing any appreciable damage to the parent plant. The leaves were collected from JSS College Garden, Mysuru. 
Swiss albino mice (Ethical Committee No: 222/2017) were obtained from central animal facility, JSS Medical College. All the experiments were approved by the institutional animal ethical committee, JSS College of Pharmacy, JSS University, Mysore, India.

\subsection{Chemicals, reagents and instrument}

All the reagents used for the synthesis were of analytical reagent grade and procured from Merck Chemicals, India. Product samples were subjected to UV-Visible NIR spectroscopic study (Agilent, CARY 60) in the range of 190-1100 nm. The interactions of extract and nanoparticles were analyzed with FT-IR spectrophotometer (Agilent FT-IR ATR Cary 630) in the range of 7000-350 $\mathrm{cm}^{-1}$. Bruker analytical instrument was employed for X-ray diffraction studies with scanning range of $20^{\circ}-80^{\circ}$ and bond angle of $3^{\circ}$. For transmission electron microscopy (TEM) imaging, a drop of aqueous solution containing the metal nanoparticles were placed and dried under an infrared lamp (JEOL JEM 2100, AC voltage $-200 \mathrm{kV})$.

\subsection{Preparation of plant extract}

Leaf extract were prepared by taking $20 \mathrm{~g}$ fresh leaves of Heliconia rostrata. These leaves were washed thoroughly with tap water followed by double distilled water \& cut into small pieces \& transferred to a beaker containing $100 \mathrm{ml}$ double distilled water. Then this solution was boiled for 10 minutes. Subsequently, the solution is filtered by using a muslin cloth followed by Whatmann no 1 filter paper and the filtrate thus obtained is the required extract solution.

\subsection{Synthesis of AgNPs}

Ten millilitre of the filtrate was added to $250 \mathrm{ml}$ Erlenmeyer flask containing $100 \mathrm{ml}$ of $2 \mathrm{mM}$ aqueous silver nitrate solutions. The mixture was subjected for shaking at rotation speed of $200 \mathrm{rpm}$. It was confirmed by the colour change of mixture from colourless to dark brown.

\subsection{Synthesis of AuNPs}

Ten millilitre of the filtrate was added to $250 \mathrm{ml}$ Erlenmeyer flask containing $100 \mathrm{ml}$ of $1 \mathrm{mM}$ aqueous $\mathrm{HAuCl}_{4} .3 \mathrm{H}_{2} \mathrm{O}$ solution. The mixture was subjected for shaking at rotation speed of $200 \mathrm{rpm}$. With the completion of synthesis, the AuNPs were further processed for purification using centrifugation as a unit operation. It was confirmed by the colour change of mixture from colourless to dark purple.

\subsection{Characterization}

The nanoparticles were monitored by UV-Vis NIR spectroscopy, the optical measurements were carried out at Agilent UV-Vis Spectrophotometer Cary 60 and a UV-Vis spectrograph of the solution of metal nanoparticles was recorded by using quartz cuvette with water as reference and scanning the spectra between $190-1100 \mathrm{~nm}$ at the resolution of $0.1 \mathrm{~nm}$.

FT-IR measurements were taken on Agilent FT-IR ATR Cary 630 with IR range: $350-7000 \mathrm{~cm}^{-1}$ from the PG Department of Chemistry, JSS College, Mysuru. Then binding properties of AgNPs and AuNPs are investigated by FT-IR analysis and the difference between the respective binding agents is verified.

The purified metal nanparticles were characterized by XRD measurements using XRD-6000 X-ray diffractometer (Bruker) and PROTO-X-ray diffractometer (AXRO Benchtop). The crystallite domain 
size was calculated from the width of the XRD peaks by assuming that they were free from non-uniform strains.

TEM samples were prepared by placing a drop of the suspension of metal nanoparticles solutions on a carbon coated copper grids and allowing water to evaporate. The samples on the copper grid were allowed to dry for $5 \mathrm{~min}$. The shape and size of metal nanoparticles were determined from TEM images. The transmission electron microscope (JEOL JEM 2100) facility was availed from Sophisticated Analysis Instrument Facility, STIC, Cochin, Kerala.

\subsection{In vivo culture of EAT cells}

EAT cells were grown in the peritoneal cavity of 6 to 8 -week-old Swiss albino mice by peritoneal transplantation of $0.5 \mathrm{ml}$ of cell suspension $\left(5 \times 10^{6}\right.$ cells $)$ in sterile saline. ${ }^{16}$ These cells grow in the mice peritoneum, forming an ascites tumor with massive abdominal swelling. The animals show a dramatic increase in body weight over the growth period and the animals succumb to the tumor burden by 12-14 days after implantation. The number of cells increases gradually with the growth of tumor, along with accumulation of excess of ascites fluid. To study the effect of the synthesized metal NPs on the inhibition of proliferation of EAT cells in vivo, 3 groups of animals (one control and two treated) were selected and transplantated with EAT cells. A minimum of six mice in each group were used for the experiment and the results obtained are an average of three individual such experiments. From the day $6^{\text {th }}, 2 \mathrm{mg} / \mathrm{kg}$ body weight of the prepared metal nanoparticles in phosphate buffer saline (PBS) was injected intraperitonealy to the test animals, while the controls were injected only with PBS. The body weight and abdominal circumference of all the animals were monitored regularly and on $12^{\text {th }}$ day, batches of test and control animals were sacrificed by cervical dislocation and the abdominal cavity was dissected, exposing the peritoneum. The ascites fluid volume and the EAT cell count and morphology were noted.

Since EAT cells grow as an ascites tumour, we measured the volume of ascites secreted from the control group treated with only PBS and the group that received the metal NPs along with PBS. Ascites fluid along with the EAT cells was collected from both groups after opening up the peritoneal cavity with a median incision on the abdominal wall. The volume of ascites obtained from both the control and treated animals was noted.

\subsection{Pro apoptotic activity on EAT cells}

The harvested cells from both the control and the test groups (gold and silver nanoparticles treated) were centrifuged at $3000 \mathrm{rpm}$ for 5 minutes and the packed cells were suspended in Phosphate buffer saline and centrifuged. Smears were made from the cell pellet obtained, fixed with methanol-acetic acid (3:1) and the morphological features of the cells were observed using different stains. Batches of both test and control smears were stained with Giemsa's stain and acridine orange-ethedium bromide stain that highlights the apoptotic morphology of the cells when observed under bright field microscope and florescent microscope respectively. ${ }^{17,18}$

\section{References}

1. Raveendran P., Fu J., and Wallen S. L. (2006). A simple and green method for the synthesis of Au, $\mathrm{Ag}$ and Au-Ag alloy nanoparticles. Green Chem., 8 (1) 34-38.

2. Huang J., Li Q., Sun D., Lu Y., Su Y., Yang X., Wang H., Shao W., He N., Hong J., and Chen C. (2007). Biosynthesis of silver and gold nanoparticles by novel sundried Cinnamomum camphora leaf. Nanotechnol., 18 (10) 105104-105115.

3. Hashmi S. K., and Hutchings G. J. (2006). Gold catalysis. Angew. Chem. Int. Ed., 45 (47) 78967936. 
4. Magudapathy P., Gangopadhyay P., Panigrahi B. K., Nair K. G. M., and Dhara S. (2001). Electrical transport studies of Ag nanoclusters embedded in glass matrix. Physica B, 299 (1-2) 142-146.

5. Bruno A O., and David J. F. (2004). Sparse coding of sensory inputs. Curr. Opin. Neurol., 14 (4) 481-487.

6. Rao C. N. R., and Cheetham A. K. (2001). Science and technology of nanomaterials: current status and future prospects. J. Mater. Chem. 11 (12) 2887-2894.

7. Zhang S. X., Wang N., Yu H. J., Niu, Y. M., and Sun C. Q. (2005). Covalent attachment of glucose oxidase to an $\mathrm{Au}$ electrode modified with gold nanoparticles for use as glucose biosensor. Bioelectrochem., 67 (1) 15-22.

8. Sun Y., and Xia Y. (2002). Shape-controlled synthesis of gold and silver nanoparticles. Science, 298 (5601) 2176-2179.

9. EI-Sayed H., Huang X., and EI-Sayed M. A. (2006). Selective laser photo-thermal therapy of epithelial carcinoma using anti-EGFR antibody conjugated gold nanoparticles. Cancer Lett., 239 (1) $129-135$.

10. Brako L., and Zarucchi J. L. (2016). Catalogue of the flowering plants and gymnosperms of peru. Monogr. Syst. Bot. Mo. Bot. Gard., 45 (i-xl) 1286-1287.

11. Mathina and Rajalakshmi R. (2016). Heliconia rostrata flower extract-A new eco-friendly inhibitor for mild steel acid corrosion. Chem. Sci. Rev. Lett., 5 (17) 72-82.

12. Geetha R., Ashokkumar T., Tamilselvan S., Govindaraju, Sadiq M., and Singaravelu G. (2013). Green synthesis of gold nanoparticles and their anticancer activity. Cancer Nano., 4 (4-5) 91-98.

13. Sasikala, Linga Rao M., Savithramma N., and Prasad T. N. V. K. V. (2015). Synthesis of silver nanoparticles from stem bark of Cochlospermum religiosum (L.) Alston: an important medicinal plant and evaluation of their antimicrobial efficacy. Appl. Nanosci., 5 (7) 827-835.

14. Ravichandran V., Tiah Z. X., Subashini G., Terence F. W. X., Eddy F. C. Y., Nelson J., and Sokkalingam A. D. (2011). Biosynthesis of silver nanoparticles using mangosteen leaf extract and evaluation of their antimicrobial activities. J. Saudi. Chem. Soc., 15 (2) 113-120.

15. Rosarin F. S., Arulmozhi V., Nagarajan S., and Mirunalini S. (2013) Antiproliferative effect of silver nanoparticles synthesized using amla on Hep2 cell line. Asian Pac. J. Trop. Med., 6 (1) 1-10.

16. Rekha N. D., Aradhya S. M., and Jayashree K. (2015). The antiangiogenic, antioxidant and proapototic chemopreventive properties of tannins from memecylon malabaricum. Int. J. Pharm. Sci. Res., 6 (1) 259-266.

17. Belakavadi M., and Salimath B. P. (2005). Mechanism of inhibition of ascites tumor growth in mice by curcumin is mediated by NF-kB and caspase activated dnase. Mol. Cell Biochem., 273 (1-2) $57-$ 67.

18. Danladi J., Mariga A. A., Yaro J. D., Ahmed S. A., and Akpulu S. P. (2013). Comparative studies of dry and wet cervical smear in human. Asian J. Med. Chem., 5 (2) 41-43.

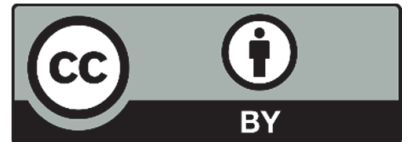

(C) 2018 by the authors; licensee Growing Science, Canada. This is an open access article distributed under the terms and conditions of the Creative Commons Attribution (CC-BY) license (http://creativecommons.org/licenses/by/4.0/). 